\title{
What is the nature and extent of student-university mismatch?
}

\section{Students do worse if their abilities fail to match the requirements of the institutions where they matriculate}

Keywords: student ability, university quality, higher education

\section{ELEVATOR PITCH}

A growing body of research has begun to examine the match between student ability and university quality. Initial research focused on overmatch-where students are lower attaining than their college peers. However, more recently, attention has turned to undermatch, where students attend institutions with lower attaining peers. Both have been shown to matter for student outcomes; while in theory overmatch could be desirable, there is evidence that overmatched students are less likely to graduate college. Undermatched students, meanwhile, have been shown to experience lower graduate earnings.

\section{KEY FINDINGS}

\section{Pros}

( Researchers have a good understanding of the characteristics of mismatched students, and the drivers of mismatch.

- Mismatch is driven predominantly by student application behavior, rather than because wellmatched colleges have rejected them.

$\oplus$ Well designed and targeted information interventions have been shown to be effective in reducing undermatch by encouraging disadvantaged, academically able students to apply to, and enroll in, selective institutions.

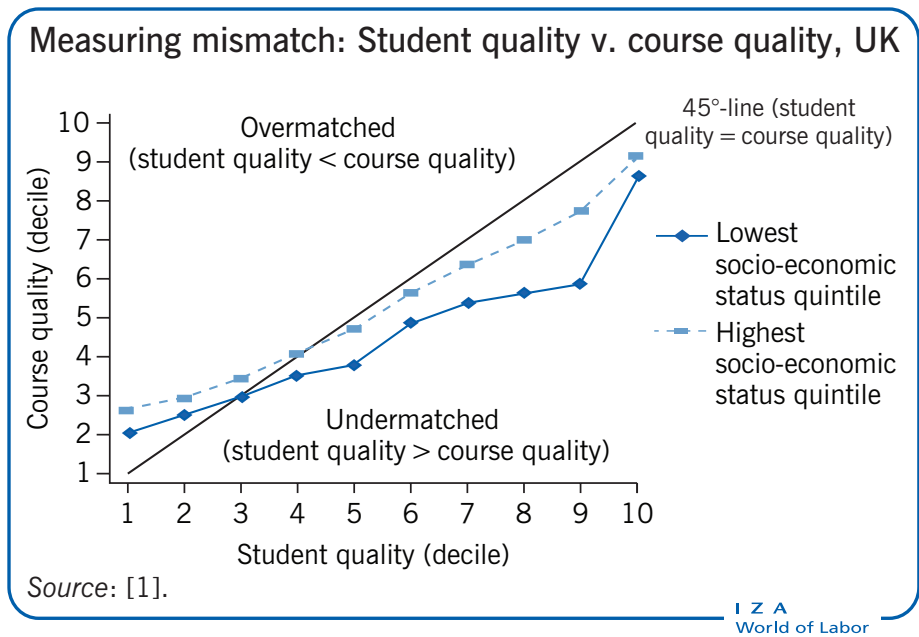

\section{Cons}

- Evidence suggests that overmatched students are less likely to graduate college.

- Undermatched students are shown to experience lower graduate earnings.

- Well-informed students have been found to overmatch more, i.e. they appear to prefer higher quality institutions even if they end up overmatching as a result.

- Disadvantaged students are more likely to undermatch and less likely to overmatch.

- There are significant research gaps on mismatch's non-cognitive drivers, the relative importance of subject choice and student preferences, and impacts on future outcomes.

\section{AUTHOR'S MAIN MESSAGE}

Evidence suggests there is a high degree of mismatch between student ability and university quality. There is consistent evidence that disadvantaged students are more likely to be undermatched and less likely to be overmatched than equally qualified students from better-off backgrounds. Lack of information, geographical isolation, and financial constraints are documented drivers, though mismatch can arise in the absence of these conditions. Highly targeted interventions such as coupling information with financial assurances have been shown to be effective at improving match. 


\section{MOTIVATION}

Increasing enrolment in higher education is an important element of governments' human capital accumulation strategies. Consequently, much academic research has been devoted to examining policies aiming to encourage students into university. However, less attention has been given to the types of universities and courses students enroll in and whether being well matched to a course is beneficial for students. Given the high degree of variation in university quality and student ability, it is important to understand how efficient the higher education market is in matching students to courses.

A well-functioning market would be one in which students attend the institution offering the highest net marginal benefit, conditional on their characteristics. Net benefits could depend on a variety of factors including preferences, cost of attendance, geography, and so on. A more simplified approach is to examine student qualifications in comparison to other students attending a given university. Using variation in student quality as a proxy for returns, it can be assumed that, all other things being equal, students will want to attend the institution with the highest returns (i.e. the highest student quality). Therefore, the extent of mismatch provides one metric of how well the higher education market is functioning; the more mismatch, the more students could benefit from making different choices. The question of mismatch is why some young people do not access top institutions when they could. For example, many Ivy League courses in the US offer free admission and generous financial support to students from low-income backgrounds, yet the vast majority of highachieving low-income students do not access them. The question is, why not?

\section{DISCUSSION OF PROS AND CONS}

\section{Does mismatch matter for student outcomes?}

Although there is some variation in the exact definitions of mismatch in this context, there are two broad types described in the literature: (i) overmatch: when students enroll at a university where they are underqualified; and (ii) undermatch: when students enroll at a university where they are overqualified.

The consequences of student-to-university mismatch are theoretically ambiguous. Overmatch may at first glance appear to be beneficial to the student, as attending a higher quality college than expected could result in a higher return. However, overmatched students may struggle to keep up with their better-prepared peers and the material being taught, potentially resulting in lower graduation rates. Being undermatched could also be beneficial in theory, if such students benefit from being a "big fish in a small pond." But it could also be problematic as attending colleges with fewer financial resources and lower prestige could potentially impact graduation rates and future earnings.

Testing the consequences of mismatch is an empirical challenge. University choices and non-cognitive traits such as motivation are highly correlated, distinguishing their effects on degree attainment and earnings is thus problematic without external sources of variation in college choice. For example, more motivated students may make "better" choices regarding which university to enroll in, and more motivated individuals would be paid more in the labor market regardless of university choice. Only a limited number of studies have overcome these challenges, but the evidence does seem to point to the finding that mismatch is important for student outcomes. 


\section{Exploring overmatch via affirmative action}

Initial interest in mismatch focused almost exclusively on overmatch arising from affirmative action policies, in which potentially underqualified minority students were given access to highly selective institutions [2]. Such studies come almost exclusively from the US, where researchers have exploited bans of affirmative action policies in different states at different times, finding mixed results [3], [4].

One such study exploiting differential timing of affirmative action bans across the US shows that after such bans, there was a decrease in the quality of schools in which underrepresented minority students enrolled [3]. However, importantly, the authors found little impact on graduation rates of minority students. By contrast, another study that focuses on the affirmative-action ban in California (Proposition 209) finds that the overall graduation rates for minorities in the University of California (UC) system increased by over 4 percentage points after the ban [4]. Probing this result further, the study concludes that this was at least in part to do with match; after the ban, minority students-who were less academically prepared-were "reshuffled" toward less selective schools or majors. These positive findings imply that less selective schools are better at graduating less well prepared students.

It should be noted, however, that overmatch due to affirmative action is actually quite rare and only occurs to a great extent in a small share of highly selective institutions. In these cases, however, the differences in academic preparation can be very large. For instance, a study from California documents that during the period of affirmative action in UC campuses, at UC Berkeley the median score of admitted minority students was at the seventh percentile of the non-minority distribution [5]. Campuses with large differences in academic preparation of students due to affirmative action experienced larger gaps in racial graduation rates.

It is also important to note that the choice of major could make mismatch more or less relevant, and that the match between the student and university is especially important in the sciences, which award lower grades and require more study time, again according to the California study [5]. The study shows that less-prepared minority students at top-ranked campuses would have higher science graduation rates had they attended lower-ranked campuses. This evidence of mismatch in the sciences was less prevalent for non-science majors; the most selective universities were found to have higher returns to graduating students with non-science majors than less selective universities, regardless of the level of student preparation.

A study from 2018 examined the potential influence of overmatch on wages, this time using a structural model which compares "status quo" affirmative action schemes with "color-blind" schemes and proportional schemes (i.e. where there is a proportional quota of minority students) [6]. In this model, more generous affirmative action schemes generally lead to higher average graduation rates for minorities, with little effect on nonminorities. Since minority students are assigned to worse colleges under a color-blind admissions system, the average household income of minority students drops relative to the status quo, while nonminority students have slightly more annual income on average. Under a proportional system, minority students increase their household income ten years after graduation due to their better college placements, while nonminority student income drops, but by a smaller amount. 


\section{Studies including both forms of mismatch}

Though less prevalent in the literature, there are studies that have examined both undermatch and overmatch. A US-wide study, which explored both undermatch and overmatch (not through studying affirmative action, but by comparing student ability to college quality), reveals complementarities between students and institutions-but only for certain outcomes. In particular, the authors of one study found evidence that higher attaining students benefit more from college quality in terms of time taken to complete a degree [7]. There is also some evidence that college fit matters for later earnings outcomes.

In a rare (and still unpublished) example of a non-US study, one author examines a form of student-to-university mismatch in Colombia. The author exploits a reform of the national university entrance exam, which resulted in low socio-economic status (SES) students doing better on the test and thus being shifted toward higher-quality colleges, displacing high SES students. This, in turn, led to poorer college outcomes and lower subsequent labor market earnings for both high- and low-income students, suggesting the change in exam resulted in mismatch, with negative consequences.

\section{Measuring the extent of mismatch}

Given that the fit between student ability and college quality seems to matter, questions such as "what is the extent of college mismatch?" and, "what types of students are affected?" are of great interest to education economists and have relevance for equity and social mobility. If talented disadvantaged students are enrolling in courses with lower returns, this undermines the potential for higher education to have a positive impact on social mobility. Empirical studies of the extent of mismatch are thus vital.

Studies examining the extent of mismatch and the types of students who mismatch are also largely US-based [8], [9], [10], [11], with one UK study to date [1]. These studies do not typically exploit affirmative action policy changes, but compare student ability to college quality to determine mismatch. How these two elements of match are measured is crucial, and this varies by study. Most studies measure student ability according to academic test scores such as the ACT or SAT in the US, or A-level results in the UK. Though some studies use the Armed Forces Vocational Aptitude Battery (ASVAB) measure of "innate" ability and are therefore arguably less affected by earlier educational decisions.

There is also variation in how university quality is measured. This can be according to the high school test scores of a university's students [1], [8] or based on composite measures of quality such as student SAT scores, rejection rates, faculty salaries, and faculty-student ratios [7], [9], or even based on the expected earnings of graduates [1] (Figure 1). The UK study goes further than simply examining match at the university level, by providing match measures at the university subject (course) level, which, as seen in the UC system, is important given the academic demands that different subjects have, even within an institution [1].

Mismatch is then calculated by comparing student attainment to university (or course) quality. For example, in a study from 2012, students are defined as matched if their ability percentile is within 20 points of their college quality percentile, and mismatched otherwise [9]. Two studies calculate a mismatch index, defined as the university/course 
quality percentile minus the student attainment percentile [1], [8]. Other studies adopt different definitions. These can involve predicting a student's probability of attendance at a certain institution type (e.g. elite, selective, non-selective) based on their academic credentials, and then comparing this to the type they actually attend [10], or defining students as mismatched if they are entitled, through affirmative action, to access a place at a selective institution, but take up a place somewhere less elite [11].

Figure 1. Mismatch based on earnings by socio-economic status (SES)

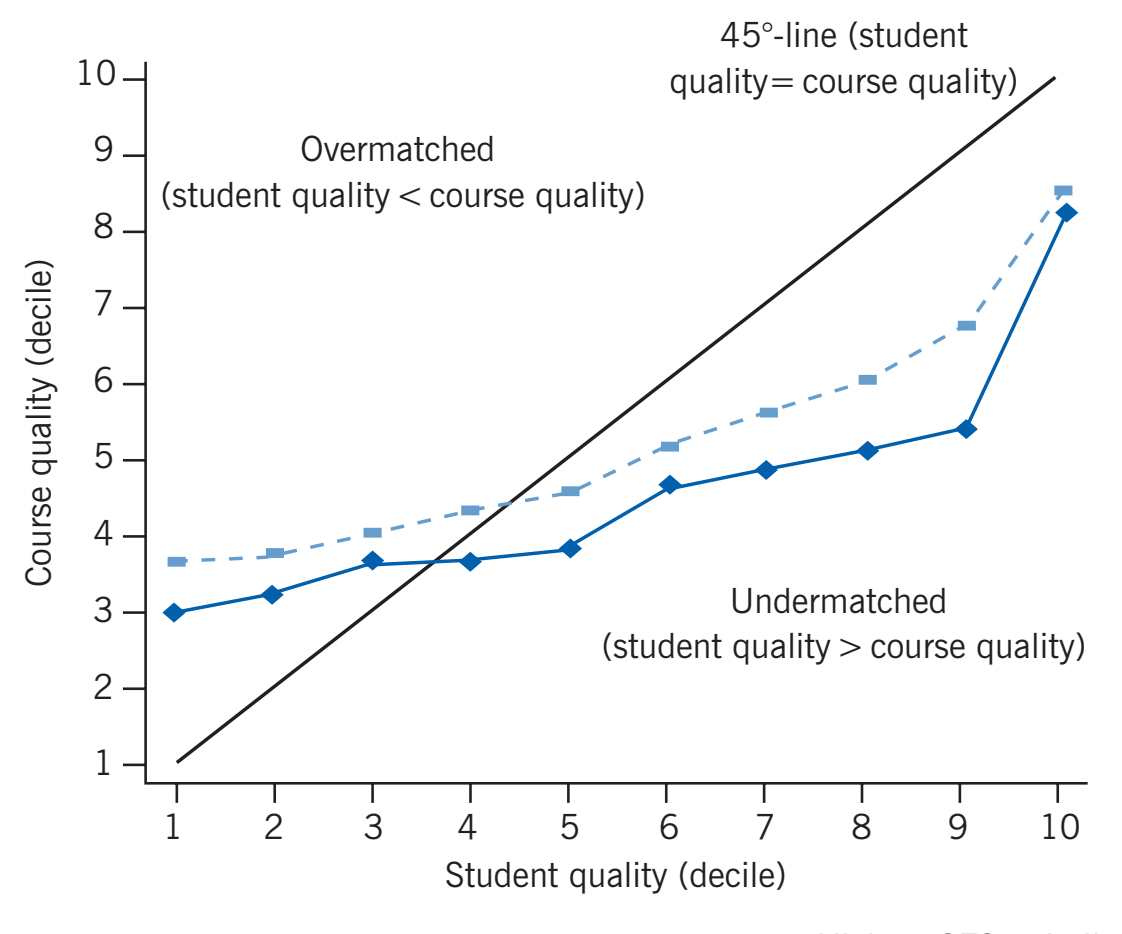

Source: Campbell, S., L. Macmillan, R. Murphy, and G. Wyness. Inequalities in Student to Course Match: Evidence from Linked Administrative Data. Centre for Economic Performance, LSE, Discussion Paper No. 1647, 2019 [1].

These studies have generated a large body of information, both about the extent of the mismatch problem and the drivers of mismatch. Indeed, it is well-established that there is a high degree of university-to-student mismatch, with estimates suggesting that around $25 \%$ of students are under- or overmatched in the US [9], [10], and $15-25 \%$ in the UK, depending on the definition [1]. There are no equivalent estimates in other developed or developing countries.

\section{Who are the mismatched students?}

Despite their various definitions, almost all studies of mismatch agree that disadvantaged low SES students are more likely to be undermatched and less likely to be overmatched. One US study shows that both parental wealth and parental education are correlated with a higher probability of undermatch and lower probability of overmatch [9]. There 
is also evidence that, in the presence of affirmative action policies, minority students still undermatch [11]. Evidence on gender gaps in match is rarer, but the study from the UK highlights a male-female gap according to one definition of match [1]. The study shows that when course quality is defined according to the average qualifications of students, men and women match to similar courses throughout the attainment distribution. However, when defining course quality on the basis of earnings of its graduates, women are more likely to be undermatched than men; at all points on the academic attainment distribution, women choose courses that are lower earning (based on the earnings of graduates six years after graduation) than men. This systematic undermatching by women into lower earning subjects could be a potential driver of the unconditional wage gap.

There is by now a wide body of evidence on the drivers of mismatch. Several studies have examined the role of student application behavior in academic mismatch, invariably finding that both undermatch and overmatch result from choices made by students, not from rejection by college admissions offices [8], [9], [10], [11]. One study, for example, shows that an important driver of undermatch arises from the fact that the vast majority of very highachieving students who are low-income do not apply to any selective college or university [8].

A number of mechanisms have also emerged from the literature. Several studies highlight the role of geography. One study shows that students who live in non-urban areas, or who live far from a selective or in-state public university are more likely to be undermatched [8], while another shows that having a well-matched in-state public university within 50 miles improves match [9]. It is important to note, however, that these studies are all from the US, where distances between homes and colleges can be large. The UK study, meanwhile, shows little evidence of geography as a driver of SES gaps [1].

Credit constraints have also been highlighted as a factor in mismatch. A 2019 study finds evidence that students from less wealthy families undermatch more when higher-quality colleges charge higher tuition [9]. This study also shows that distance to university has an important interaction with cost of attendance. Lower in-state tuition is found to correlate more strongly with mismatch for students without a closely matched public university nearby. However, even in systems with few credit constraints, mismatch is present. In the UK, where there are far fewer credit constraints since university is free at the point of entry and all students are entitled to loans for fees and living costs, there is still a high degree of mismatch.

The role of information has also been tested as a likely explanation. Though studies do not typically have access to data on how well-informed students are, a number of studies have used proxies. Students are assumed to be better informed if they live in areas with high numbers of degree holders among the population, or if they attend high schools where many pupils go to college. Students in such circumstances have been found to undermatch less [8], [9]. However, such well-informed students have also been found to overmatch more-in other words, well-informed students regardless of ability appear to prefer to attend higher-quality institutions even if they end up overmatching as a result [9].

Undermatch can arise even in situations where students are likely to be fully informed. One study examining affirmative action caused by the widely publicized Texas Top 10 Percent Plan, where students who graduate in the top $10 \%$ of their high school cohort are guaranteed a place at Texan flagship universities, finds evidence of undermatch among minority students [11]. Black and Hispanic top $10 \%$ graduates are less likely to apply 
to a top-tier flagship university compared to their white student counterparts despite widespread information that they are guaranteed admission.

In summary, these studies show strong evidence that low SES students, students that are geographically isolated, and less informed students tend to undermatch more and overmatch less. Meanwhile, students with a closely matched university that is easily accessible tend to be better matched. It is important to note, however, that the UK study shows that mismatch can occur even when credit constraints and geographical factors are minimized [1]. This highlights the need for research to go beyond looking at these factors as the explanation for mismatch.

\section{Strategies to improve the fit between students and universities}

Given there is some evidence to suggest that the fit between university and student is important for future outcomes, and that there is a large degree of mismatch present in higher education, a pertinent question is: how can match be improved? Relevant studies have focused on encouraging disadvantaged but high-attaining students to enroll in more selective universities. Interventions to improve match for such students have considered the possible mechanisms by which these students undermatch, in particular focusing on the availability of information about course quality and the costs and benefits of going to a selective university. Studies have provided students with light-touch information about the costs and benefits of particular institutions and courses, simplified the application process for college finance, or provided highly targeted information to high-achieving students. One recent study targeted high-achieving US students in Michigan with the promise of guaranteed free tuition and financial support for the entirety of their college careers [12]. Though the majority of these students would have received free tuition anyway, given their financial background, this was a highly successful intervention, suggesting these students were unaware of their eligibility for financial aid.

A similar study in the UK focused on high-achieving young people at high schools which typically send more than $20 \%$ of their high-achieving students to their nearest higher education institution [13]. The intervention was to send these pupils a letter written by a university student from their school, and with a similar background to them, encouraging them to aim for a selective institution. The letter emphasized that universities offer different opportunities, that employers care which university someone attends, and that more selective universities can actually be cheaper for students from low-income families than less selective universities. Pupils receiving the letter were significantly more likely both to apply to and accept an offer from top-20 UK universities.

\section{LIMITATIONS AND GAPS}

There are still too few studies adopting causal identification strategies to be sure of the impact of under- or overmatch on both academic and labor market outcomes. The lack of convincing and consistent evidence of the impact of both under- and overmatching on future outcomes is an important gap in the literature.

Moreover, the current definition of match may be inaccurate. Evidence from the above studies implies that mismatch can arise even in the presence of near perfect information, 
and when credit constraints are not an issue. This implies that high-achieving students from poor backgrounds may be experiencing other factors discouraging them from attending selective universities. Two likely candidates are non-cognitive factors and preferences.

First, students from disadvantaged backgrounds may have low academic self-concept (i.e. how an individual views their own academic achievement), and hence may not apply in the first place. Furthermore, those students who do attend may lack some of the noncognitive skills required to succeed, and the institutions to which these students would be well-matched may not provide the required support structure. A link between family background and non-cognitive skills has been demonstrated by past research, but the role of these so-called "soft skills" has not been fully explored in the mismatch literature.

Second, studies of mismatch typically do not take account of students' preferences. Students may appear to be academically mismatched, but they may be satisfied with their choice of institution, and may have unobserved preferences such as to be in a particular location, or to be among peers. They may also derive high rates of satisfaction from their chosen courses even if they appear to be mismatched "on paper." Earlier research points out that even if some of the ex-post outcomes for minority students are worse under affirmative action, it may be the case that such students are better off when considering a wider range of outcomes.

\section{SUMMARY AND POLICY ADVICE}

Studies from the UK and US have revealed a high incidence of both undermatch and overmatch, with the proportion of students who are mismatched ranging from 15-25\% (of each undermatch and overmatch), depending on country and context. This implies that the higher education market has considerable search frictions, which is problematic given the small body of evidence establishing the existence of complementarities in student ability and college quality. Therefore, policymakers should aim to improve the match of students to institutions and courses by removing these frictions and so ensure that high-ability students choose to attend more selective universities.

Most studies agree that students from disadvantaged backgrounds and geographically isolated students are most likely to be undermatched, thus presenting a potential target population for policy to relieve undermatch. Other studies have shown that minority students undermatch, even in the presence of affirmative action, and that females are more likely to be undermatched than males when course quality is measured according to graduates' earnings.

Encouraging high-attaining but disadvantaged students to attend better quality universities and courses is important from a social mobility perspective. Recent evidence suggests that the institution chosen and subject studied are important for future labor market returns. Thus, improving the choices of disadvantaged students is likely to improve intergenerational mobility.

In addition to the well documented SES gaps in student choices, research from the UK also finds evidence of a gender gap in match when considering the returns of specific majors. This gender gap-showing that high-attaining females choose equally selective 
courses than males, but ones associated with lower earnings-is comparable in size to the SES gap and is also, therefore, worthy of investigation and action.

So, what can policymakers do? There are a number of strategies potentially open to policymakers concerned with improving the fit between students and institutions. However, the success of these policies will depend on context. Research points to the role of information provision as a relatively cheap and effective strategy to reduce undermatch of high-attaining, low SES students. The information interventions described above had very encouraging positive results and suggest a potential way forward for policymakers.

\section{Acknowledgements}

The authors thank anonymous referees and the IZA World of Labor editors for many helpful suggestions on earlier drafts.

\section{Competing interests}

The IZA World of Labor project is committed to the IZA Code of Conduct. The authors declare to have observed the principles outlined in the code.

(C) Gillian Wyness and Richard Murphy 


\section{REFERENCES}

\section{Further reading}

Arcidiacono, P., E. Aucejo, H. Fang, and K. Spenner. "Does affirmative action lead to mismatch? A new test and evidence." Quantitative Economics 2:3 (2011): 303-333.

Hoxby, C., and S. Turner. Expanding College Opportunities for High-Achieving, Low Income Students. SIEPR Discussion Paper No. 12-014, 2013.

\section{Key references}

[1] Campbell, S., L. Macmillan, R. Murphy, and G. Wyness. Inequalities in Student to Course Match: Evidence from Linked Administrative Data. Centre for Economic Performance, LSE, Discussion Paper No. 1647, 2019.

[2] Arcidiacono, P., and M. Lovenheim. "Affirmative action and the quality-fit trade-off." Journal of Economic Literature 54:1 (2016): 3-51.

[3] Hinrichs, P. "The effects of affirmative action bans on college enrollment, educational attainment, and the demographic composition of universities." The Review of Economics and Statistics 94:3 (2012): 712-722.

[4] Arcidiacono, P., E. M. Aucejo, P. Coate, and V. J. Hotz. "Affirmative action and university fit: Evidence from Proposition 209." IZA Journal of Labor Economics 3:1 (2014): 7.

[5] Arcidiacono, P., E. M. Aucejo, and V. J. Hotz. "University differences in the graduation of minorities in STEM fields: Evidence from California." American Economic Review 106:3 (2016): 525-562.

[6] Bodoh-Creed, A., and B. R. Hickman. Pre-College Human Capital Investments and Affirmative Action: A Structural Policy Analysis of US College Admissions. Becker Friedman Institute for Research in Economics Working Paper No. 2017-10, 2017.

[7] Dillon, E. W., and J. A. Smith. "The consequences of academic match between students and colleges." Journal of Human Resources (Forthcoming).

[8] Hoxby, C. M., and C. Avery. The Missing "One-offs": The Hidden Supply of High-Achieving, Low Income Students. NBER Working Paper No. 18586, 2012.

[9] Dillon, E. W., and J. A. Smith. "Determinants of the match between student ability and college quality." Journal of Labor Economics 35:1 (2017): 45-66.

[10] Smith, J., M. Pender, and J. Howell. "The full extent of student-college academic undermatch." Economics of Education Review 32 (2013): 247-261.

[11] Black, S. E., K. E. Cortes, and J. Arnold Lincove. "Academic undermatching of high-achieving minority students: Evidence from race-neutral and holistic admissions policies." American Economic Review 105:5 (2015): 604-610.

[12] Dynarski, S., C. J. Libassi, K. Michelmore, and S. Owen. Closing the Gap: The Effect of a Targeted, Tuition-free Promise on College Choices of High-achieving, Low-income Students. NBER Working Paper No. 25349, 2018.

[13] Sanders, M., R. Chande, and E. Selley. Encouraging People into University. London: Behavioural Insights Team, Department for Education, 2017.

\section{Online extras}

The full reference list for this article is available from:

https://wol.iza.org/articles/what-is-the-nature-and-extent-of-student-university-mismatch

View the evidence map for this article:

https://wol.iza.org/articles/what-is-the-nature-and-extent-of-student-university-mismatch/map 